\title{
Penerapan Metoda Adaptive Reuse pada Alih Fungsi Bangunan Gudang Pabrik Badjoe Menjadi Kafetaria
}

\author{
Widya Primatiana Susanto, Raima Dien Medina, Adanthi Maudy Adwitya P \\ Program Studi Arsitektur, Fakultas Arsitektur dan Desain \\ Institut Teknologi Nasional Bandung \\ Email: widyaprimatiana@gmail.com
}

\begin{abstract}
ABSTRAK
Penelitian ini bertujuan untuk mempelajari penerapan metoda adaptive reuse pada sebuah bangunan ex gudang pabrik baju yang sudah tidak digunakan lagi. Maraknya bisnis factory outlet dan strategisnya lokasi memberi ide kepada pemilik pabrik untuk tidak menghancurkan gudang tersebut tetapi merubahnya menjadi sebuah bangunan komersil dengan fungsi kafetaria. Ide ini sejalan dengan isu sustainable yang menerapkan konsep $3 R$ yaitu reduce,reuse dan recycle yang pada bangunan dikenal sebagai adaptive reuse. Dengan mempelajari sejarah bangunan dan melakukan observasi ke objek maka diperoleh gambaran penerapan konsep adaptive reuse. Alih fungsi mendorong terjadinya perubahan, terutama pada ruang dalam sebagai bentuk adaptasi terhadap fungsi baru. Bagaimana potensi yang dimiliki bangunan, seperti tinggi plafond, lebar dan luas bangunan, perletakan jendela dan lubang angin dapat dipertahankan dan dioptimalkan untuk fungsi baru. Sedangkan perubahan pada facade bangunan dimaksudkan untuk memperindah tampilan sehingga bangunan terlihat indah dan dapat menarik banyak pengunjung. Metoda adaptive reuse cocok dengan issue sustainable sehingga bangunan lebih baik dialih fungsikan daripada dihancurkan. Untuk menunjang issue sustainable diperlukan campur tangan pemerintah dalam mengatur pembangunan sehingga ratio area terbangun dan tidak terbangun di kota Bandung dapat seimbang.
\end{abstract}

Kata kunci: adaptive reuse, transformasi, sustainable building.

\begin{abstract}
This research is intended to study the application of the adaptive reuse method on an unused clothing warehouse building. The emerging of the outlet factory business and the strategic location of the building give the factory owner ideas not to knock down the warehouse but instead change it into a commercial building function as a cafeteria. This idea is in line with the sustainable issue which apply the 3R concept: Reduce, Reuse, and Recycle or known as an adaptive reuse. By studying the building history and observing the object, an image of the adaptive reuse concept application could be gained. The function shift pushes to changes, especially in the inner room as an adaptation to the new function. How this building potential such as the ceiling high, wide and spacious, window and opening placement could be maintained and optimized to a new function. Whilst the building facade alteration is intended to beautify performance so the building looks picturesque and could attract many visitors. The adaptive reuse method is suitable for the sustainable issue so it is better to switch the function rather than to devastate it. To support the sustainable issue the intervention by the government is needed to organize the development so the ratio between the built and non built area in Bandung city could be balanced
\end{abstract}

Keywords: adaptive reuse, transformation, sustainable building. 


\section{PENDAHULUAN}

Kualitas hidup manusia yang terus menurun diakibatkan oleh perubahan iklim karena konsentrasi gas rumah kaca yang berlebih dan mengakibatkan kenaikan suhu bumi. Menurut penelitian yang dilakukan oleh United Nations Environment Programme atau UNEP (2007), bangunan merupakan salah satu aspek dengan presentase terbesar yang mempengaruhi perubahan iklim di dunia. "The building sector contributes up to $30 \%$ of global annual greenhouse gas emissions and consumes up to $40 \%$ of all energy". [1] Untuk menanggulangi masalah tersebut, diperlukan konsep green building pada bangunan yang dapat mereduksi dampak buruk dari bangunan, salah satu prinsip yang digunakan adalah adaptive reuse building. Adaptive reuse yang dimaksud disini adalah menggunakan kembali bangunan untuk fungsi berbeda dari fungsi awal[2].

Dalam kaitannya dengan kondisi kota Bandung saat ini yang sudah sangat kekurangan lahan hijau, maka adaptive reuse diharapkan dapat mengurangi bertambahnya lahan terbangun. Dengan mengoptimalkan lahan atau bangunan yang sudah ada diharapkan tidak ada lagi pembangunan baru terutama di kawasan pusat kota. Sejalan dengan hal tersebut saat ini Pemerintah Daerah sedang menggalakkan pembangunan ke arah vertikal terutama di kawasan pemukiman dengan pembangunan rumah susun maupun apartemen (multi family unit). Hal ini bertujuan agar dapat memenuhi meningkatnya kebutuhan akan hunian dan terbatasnya lahan di kota. Saat ini tipe hunian vertikal menjadi salah satu karakter hunian di kawasan kota.

Penelitian ini bertujuan untuk mempelajari penerapan konsep adaptive reuse pada alih fungsi gudang pabrik baju menjadi kafetaria dengan mengoptimalkan potensi bangunan yang dimiliki. Bagaimana transformasi dan adaptasi terutama pada elemen-elemen ruang dalam? Objek dipilih karena dianggap menarik, gudang pabrik sebagai passive building bertransformasi menjadi active building yang tentu saja memerlukan berbagai adaptasi, baik pada ruang dalam maupun pada ruang luar karena fungsi baru sangat berlainan dengan fungsi lama bangunan.

Keberhasilan penerapan metoda adaptive reuse pada ex gudang pabrik Badjoe diharapkan dapat diterapkan pada bangunan-bangunan yang sudah tidak digunakan dengan kondisi masih layak pakai di kota Bandung. Metoda ini sangat cocok terutama diterapkan pada bangunan cagar budaya sehingga dapat melestarikan bangunan sebagai warisan budaya. Diharapkan campur tangan Pemerintah Daerah untuk mengatur perubahan yang terjadi dan diharapkan dapat tercipta keseimbangan yang harmonis antara lahan terbangun dan tidak terbangun di kota Bandung sehingga dapat meningkatkan mutu sumber daya alam yang dimiliki.

\section{METODOLOGI}

Penelitian ini merupakan penelitian kualitatif dengan menggunakan pendekatan induktif, yaitu berupa proses pengambilan kesimpulan berdasarkan dengan fakta dan data yang sudah didapatkan melalui survey ke objek penelitian, ex gudang pabrik di Bandung. Adapun data yang diperlukan adalah penerapan konsep adaptive reuse pada bangunan Dapoer-nya Paberik yang meliputi sejarah bangunan, konsep perancangan dan bagaimana transformasi dan adaptasi yang terjadi pada ruang dalam bangunan sebagai akibat dari alih fungsi bangunan. Selain itu dilakukan pula studi literatur untuk memperoleh data sejarah bangunan, perubahan kondisi sosial, budaya dan ekonomi di kota Bandung yang berdampak terhadap menurunnya aktivitas di pabrik baju yang telah beroperasi cukup lama. Analisis dilakuan melalui pengambilan kuisioner serta pengamatan yang dilakukan di lapangan. Observasi dimaksudkan untuk mendapatkan hasil berupa data yang akan dijadikan sebuah perbadingan. Selain itu pengamatan bangunan ditujukan pula untuk mengetahui potensi apa saja yang dapat dipertahankan dan digunakan serta bagaimana cara mengatasi dan merespon kendala yang terdapat pada bangunan sebelumnya. Hasil 
analisis akan menghasilkan perbandingan antara bangunan sebelumnya dan bangunan saat ini, baik dalam aspek fungsi, fisik, dan kenyamanan bangunan.

\section{KAJIAN TEORITIS}

\subsection{Transformasi}

Menurut Gatot Adi Susilo [3] dalam kajiannya tentang "Transformasi dalam Arsitektur Jawa", Transformasi dapat diartikan mengadakan perubahan yang meliputi pada bentuk, tampilan luar, kondisi alam atau fungsinya, dan transformasi juga dapat diartikan merubah karakter pribadi. Dalam bidang Arsitektur, transformasi berkaitan dengan proses-proses perubahan bentuk dari keadan awal menjadi keadaan yang baru. Sedangkan menurut Alexander [4] transformasi adalah sebuah proses yang lambat dan tidak terduga dengan pergeseran awal dan akhir, tergantung pada faktor-faktor yang memengaruhinya.

\subsection{Adaptive Reuse}

Menurut Burchell dan Listokin [5], adaptive reuse didefinisikan sebagai sebuah strategi revitalisasi yang pekerjaannya terkait untuk merencanakan, memperoleh, mengolah, dan menggunakan kembali sebuah bangunan terbengkalai. Adaptive reuse merupakan penggunaan kembali suatu bangunan untuk menekan penyebaran pembangunan ataupun untuk mengurangi biaya pembangunan. Menurut Kim Donghwan [6] definisi adaptive reuse adalah bahwa ketika bangunan tua dan menjadi tidak sesuai untuk penggunaannya karena perkembangan teknologi, kebijakan, dan pengembangan ekonomi, maka adaptive reuse dianggap sebagai strategi berkelanjutan untuk penggunaan kembali site atau bangunan.

\subsection{Sustainable Building}

Menurut Green Building Council Indonesia (GBCI) penilaian mengenai bangunan hijau atau bangunan berkelanjutan terdiri dari lima tipe objek, yaitu penilaian untuk bangunan baru, bangunan eksisting, ruang interior, bangunan rumah dan lingkungan atau daerah sekitar (neighborhood). Sedangakan menurut Akadiri, Chinyio, \& Olomolaiye [7] sustainable building atau bangunan berkelanjutan adalah suatu konsep pengembangan yang berkelanjutan berkaitan dengan isu lingkungan, sosial, dan ekonomi. Konsep ini mengacu pada proses pembangunan yang berdampak minim terhadap lingkungan, limbah produksi, ataupun penggunanan material yang dapat di gunakan kembali (reuse).

\section{HASIL DAN PEMBAHASAN}

\subsection{Deskripsi Objek Penelitian}

1. Lokasi bangunan yang dijadikan objek penelitian berada di Jalan Soekarno Hatta no. 53, Bandung. Menurut RTRW Kota Bandung, Jalan Soekarno Hatta merupakan jalan dengan kelas jalan arteri primer dan berada di kawasan perdagangan dan jasa. Kafetaria Dapoer-nya Paberik merupakan salah satu bangunan yang berada di kawasan industri Paberik Badjoe milik PT. Delami Garment Industries. Bangunan seluas $\pm 1.758 \mathrm{~m}^{2}$ terbangun diatas site seluas $\pm 40.285 \mathrm{~m}^{2}$. Bangunan ini berbatasan langsung dengan beberapa area, pada bagian utara berbatasan langsung dengan pemukiman warga, bagian selatan berbatasan dengan kantor Tribun Jabar, bagian timur berbatasan dengan BP3TKI Bandung, dan barat berbatasan langsung dengan Dinas Tenaga Kerja dan Transmigrasi.

Bangunan Kafetaria Dapoer-nya Paberik ini berada di tengah kawasan industri Paberik Badjoe, sebelum menjadi kafetaria, bangunan ini merupakan dua massa bangunan yang berfungsi sebagai gudang penyimpanan kain untuk bahan baku dari produksi pakaian pabrik PT. Delami, dan untuk proses produksi pakaian. 


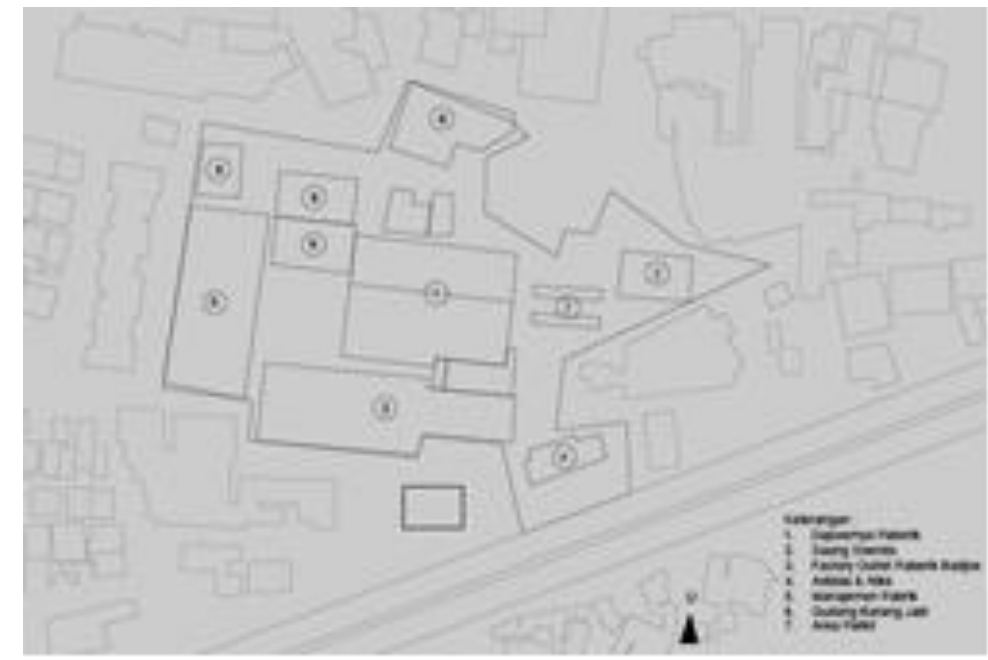

Gambar 1. Peta kawasan Paberik Badjoe (hasil survey, 2019)

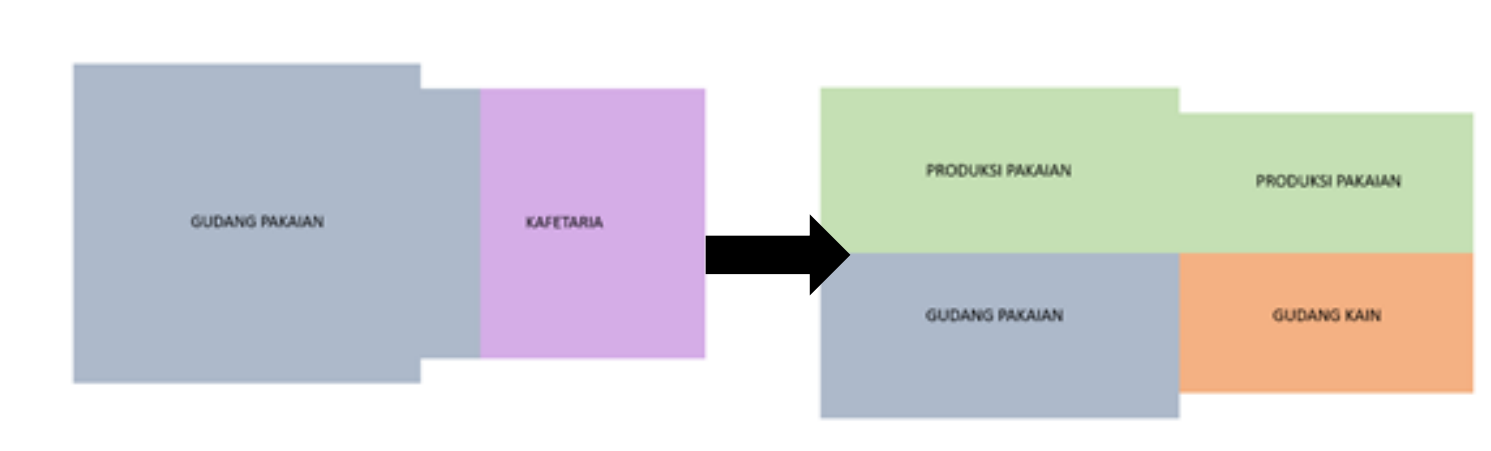

Gambar 2. Perubahan zoning pada bangunan (hasil analisis, 2019)

\subsection{Potensi Bangunan}

Beberapa aspek pada bangunan lama yang berpotensi untuk digunakan kembali dan dapat menunjang serta meningkatkan kualitas kenyaman bangunan dengan fungsi baru kafetraia, diantaranya adalah zoning ruang dalam bangunan pabrik, bukaan, dan ventilasi serta struktur bangunan.

\section{a. Struktur Bangunan}

Bangunan pabrik menggunakan sistem struktur bentang lebar, karena alih fungsi bangunan menjadi kafetaria hanya terjadi pada bagian depan bangunan, maka sistem struktur yang sudah ada dapat tetap dipakai dan tidak perlu diubah.

\section{b. Bukaan Bangunan}

Bukaan pada dinding bangunan pabrik berupa glass block dan bukaan kaca bisa dimanfaatkan dan menjadi potensi pada bangunan, sehingga dalam pengalihan fungsi bangunan pabrik menjadi kafetaria bukaan-bukaan tersebut dapat digunakan kembali.

\section{c. Ventilasi Bangunan}

Ketersediaan ventilasi dan exhaust pada bangunan pabrik menjadi nilai lebih karena keduanya dapat digunakan kembali pada bangunan dengan fungsi baru untuk tercapainya kenyamanan dalam penghawaan ruangan.

\section{d. Zoning Bangunan}

Pada fungsi banguan pabrik, zoning ruang hanya untuk fungsi gudang dan produksi pakaian, pada bagian dalam dua fungsi ruangan tersebut tidak ada tembok penghalang maupun sekat-sekat penghalang ruang sehingga menjadi potensi bangunan karena saat peralihan fungsi bangunan menjadi lebih mudah untuk ditata. 
Tabel 1. Hasil analisa perubahan fungsi bangunan

\begin{tabular}{lll} 
No. Sebelum & \multicolumn{2}{c}{ Keterangan } \\
\hline 1. & $\begin{array}{l}\text { Alih fungsi bangunan } \\
\text { disebabkan karena adanya } \\
\text { perpindahan aktivitas pabrik ke } \\
\text { Purbalingga. Perpindahan itu } \\
\text { dikarenakan tingginya nilai } \\
\text { produksi di kota Bandung } \\
\text { sehingga keuntungan tidak } \\
\text { sebanding dengan harga } \\
\text { produksi. }\end{array}$ \\
2.
\end{tabular}

\section{B. Analisa Perubahan Fisik Bangunan}

Terdapat beberapa perubahan fisik yang terjadi pada bangunan gudang dan area produksi yang dapat diamati secara langsung setelah dialih fungsikan menjadi bangunan Dapoer-nya Paberik. Perubahan yang diamati berupa perubahan pada fasad bangunan, struktur, dan pengolahan ruang dalam pada bangunan.

Tabel 2. Hasil analisa perubahan fisik bangunan

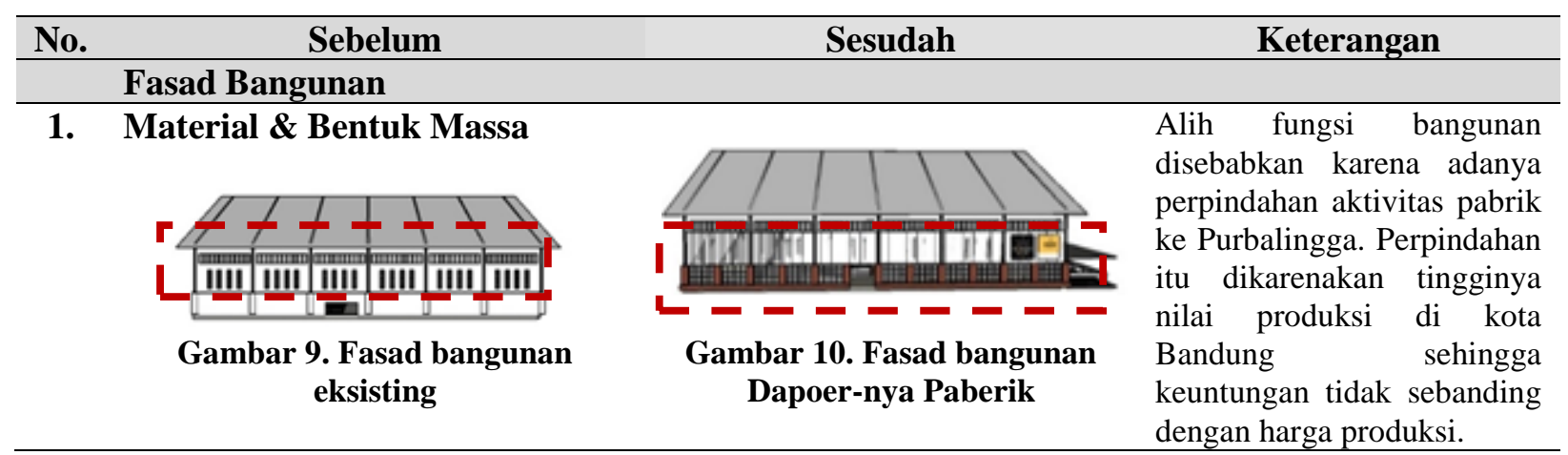




\begin{tabular}{|c|c|c|c|}
\hline No. & Sebelum & Sesudah & Keterangan \\
\hline 2. & $\begin{array}{c}\text { Gambar 11. Perspektif bangunan } \\
\text { eksisting }\end{array}$ & $\begin{array}{c}\text { Gambar 12. Perspektif } \\
\text { bangunan Dapoer-nya Paberik }\end{array}$ & $\begin{array}{l}\text { Glass block yang terdapat } \\
\text { pada bangunan eksisting } \\
\text { tidak digunakan kembali } \\
\text { pada bangunan baru. Glass } \\
\text { block ditutup dengan } \\
\text { menggunakan metal deck, } \\
\text { hal tersebut bertujuan untuk } \\
\text { memberi pembeda pada } \\
\text { bangunan baru, dan untuk } \\
\text { mengatur pencahayaan } \\
\text { bangunan. }\end{array}$ \\
\hline
\end{tabular}

1. Jenis Struktur

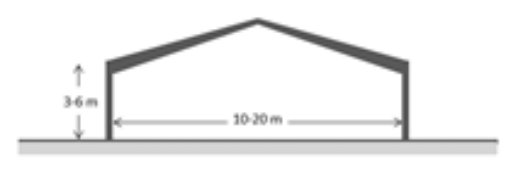

Gambar 13. Struktur bangunan eksisting

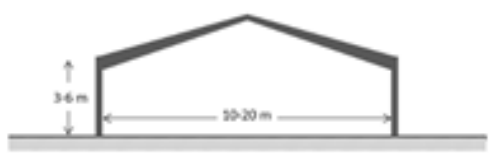

Gambar 14. Sttruktur bangunan Dapoer-nya Paberik

Struktur bangunan lama tetap digunakan untuk menekan biaya pembangunan. Bentang struktur bangunan yaitu 21.85 meter. Struktur dengan jenis bentang lebar mampu beradaptasi dengan berbagai fungsi bangunan,

\section{Material Struktur}

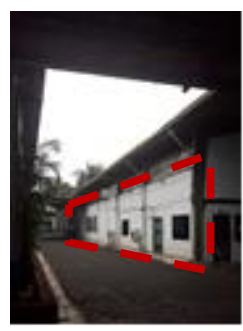

Gambar 15. Dinding dan struktur eksisting

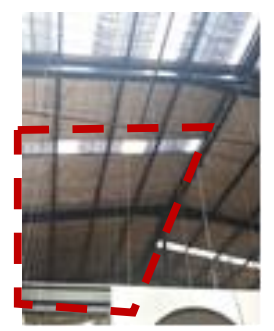

Gambar 17. Penutup metal deck

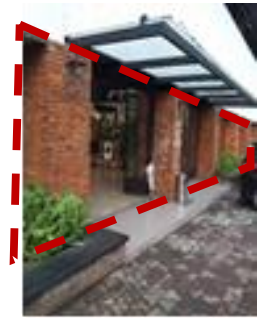

Gambar 16. Dinding dan kolom komposit Dapoer-nya Paberik

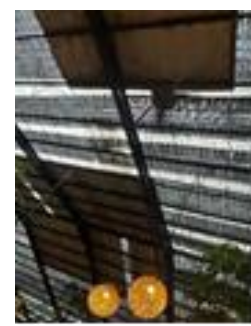

Gambar 18. Penutup atap transparan

Dilakukan beberapa penyesuaian pada struktur bangunan seperti pengecatan struktur baja, penggunaan kolom sebagai sarana utilitas, perubahan kolom komposit finishing cat putih menjadi bata ekspos, perubahan pada material penutup atap massif menjadi transparan. Penyesuaian ini dilakukan untuk menunjang kenyamanan kafetaria dan untuk memperindah visual dari bangunan Dapoer-nya Paberik.

\section{Pengolahan Ruang Dalam}

1. Konsep Interior

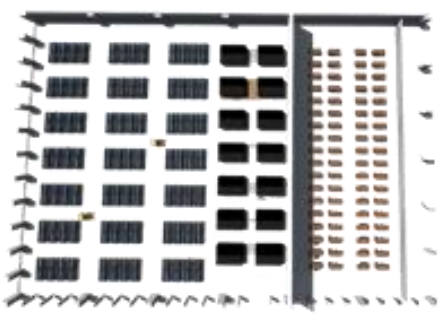

Gambar 19. Ilustrasi denah eksisting

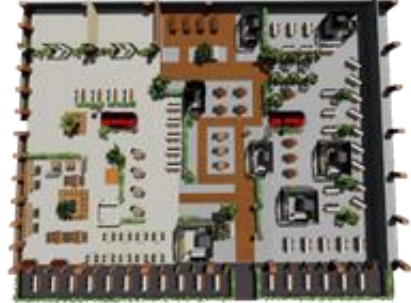

Gambar 20. Ilustrasi denah Dapoer-nya Paberik
Digunakan konsep industrial tropis pada bangunan Dapoer-nya Paberik, pemilihan konsep dipertimbangkan berdasar lingkungan dan konsep kawasan PT. Delami yang merupakan kawasan industri, namun diberikan aksen tropis dengan penggunaan berbagai tanaman pada bagian dalam 


\begin{tabular}{|c|c|c|c|}
\hline No. & Sebelum & Sesudah & Keterangan \\
\hline & & & $\begin{array}{l}\text { ruangan untuk menambah } \\
\text { kenyamanan dan keunikan } \\
\text { desain ruang dalam. }\end{array}$ \\
\hline
\end{tabular}

\section{Pembagian Zonasi}

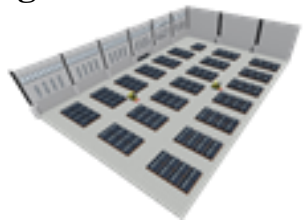

Gambar 21. Zona 1 (Gudang Bahan Mentah)

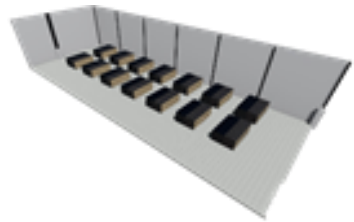

Gambar 23. Zona 2 (Gudang Aksesoris)

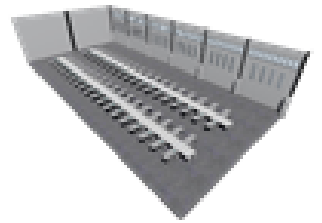

Gambar 25. Zona 3 (Area Produksi)

3. Penataan Ruang Dalam

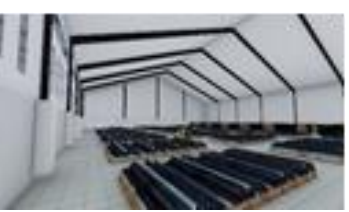

Gambar 27. Area Gudang 1

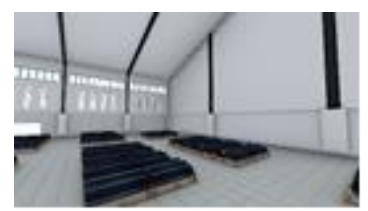

Gambar 29. Area Gudang 2

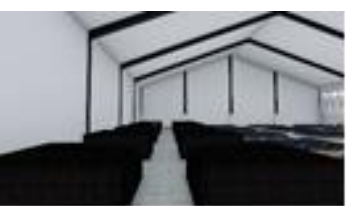

Gambar 31. Area Gudang 3

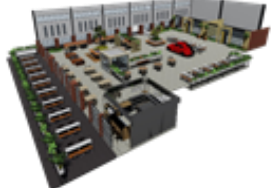

Gambar 22. Zona 1 Dapoer-nya Paberik

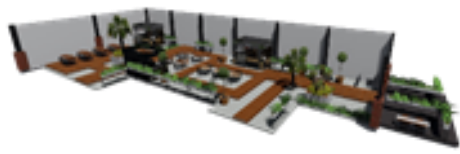

Gambar 24. Zona 2 Dapoer-nya Paberik

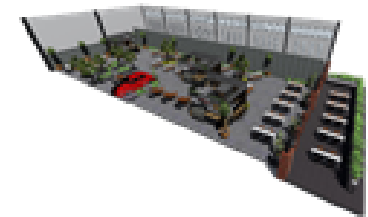

Gambar 26. Zona 3 Dapoer-nya Paberik

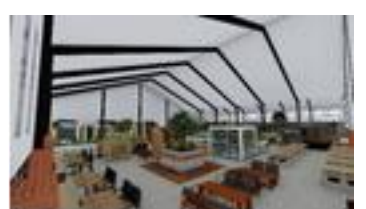

Gambar 28. Area Makan 1
Pada bangunan eksisting, tidak terdapat pembagian zonasi ruang yang spesifik. Perubahan fungsi bangunan membuat bangunan terbagi dalam beberapa zonasi. Hal ini ditujukan untuk memberikan kesan berbeda pada setiap zona agar tidak terkesan monoton. Setiap zona pada bangunan memiliki ciri khas masingmasing yang dapat dilihat dari pengolahan finishing material maupun penataan ruang.

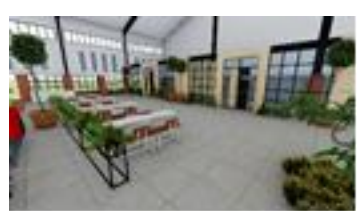

Gambar 30. Area Makan 2 dan Ruang Meeting

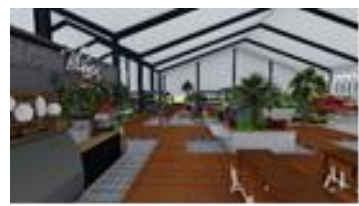

Gambar 32. Area Makan 3
Dalam penataan sebelumnya, bangunan eksisting dibuat seefisien mungkin untuk menjadi area produksi dan gudang. Sirkulasi dibuat sejelas mungkin dan lebar sirkulasi sekitar 1-2 meter.

Pada bangunan Dapoer-nya Paberik, Ruang dalam bangunan ditata secara acak dan cenderung tidak teratur. Sirkulasi dibuat lebar dan leluasa. Untuk memperjelas arah sirkulasi maka dibuat beberapa batasan berupa tanaman, palet kayu, serta aksen-aksen tertentu. 


\begin{tabular}{lll}
\hline No. Sebelum & Keterangan \\
\hline Gambar 33. Area Produksi & Gambar 34. Area Makan 6 & $\begin{array}{l}\text { Penempatan tanaman pada } \\
\text { ruang dalam bangunan } \\
\text { memberi kesan sejuk dan } \\
\text { menghidupkan suana } \\
\text { didalamnya. Dalam hal ini, } \\
\text { tanaman akan diganti secara } \\
\text { rutin sesuai dengan waktu } \\
\text { yang telah ditetapkan. Setiap } \\
\text { jenis tanaman memiliki } \\
\text { masing-masing cadangan } \\
\text { dengan jenis yang sama. }\end{array}$ \\
Gambar 35. Eksterior Area \\
Gudang
\end{tabular}

\section{Elemen dan Material Interior}

\section{Elemen Interior}

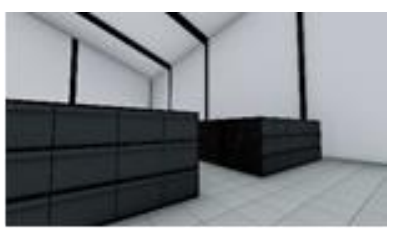

Gambar 37. Lemari besi

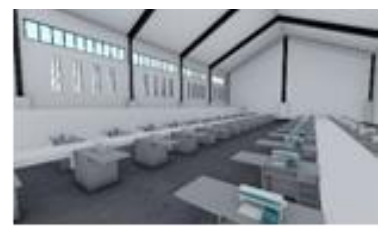

Gambar 39. Meja jahit

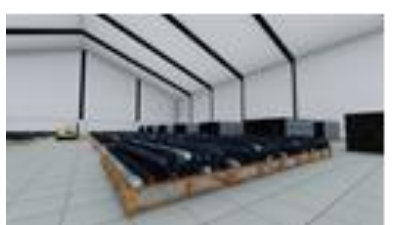

Gambar 41. Susunan kain di atas parket

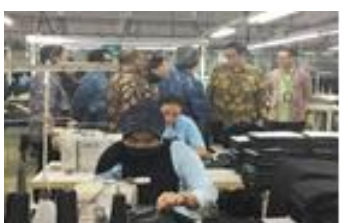

Gambar 43. Lampu pabrik Sumber:

https://news.trubus.id/baca/2213/indu stri-garmen-indonesia-berpeluangmaju-di-masa-mendatang

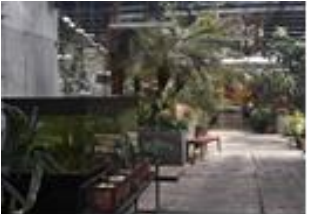

Gambar 38. Tanaman dan akuarium

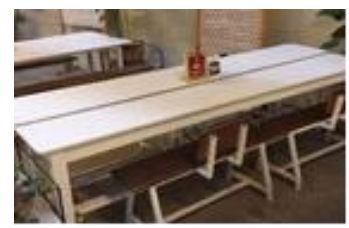

Gambar 40. Meja dan Kursi

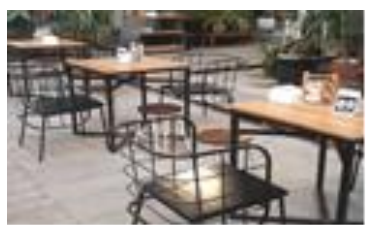

Gambar 42. Meja dan Kursi

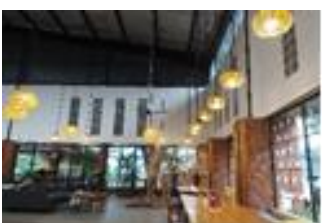

Gambar 44. Lampu kafetaria

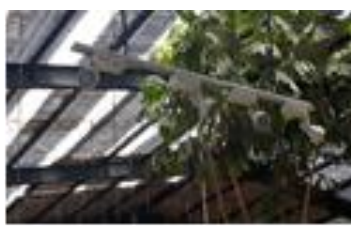

Gambar 45. Lampu kafetaria
Pada bangunan gudang dan area produksi terdapat elemen interior berupa lemari besi sebagai penyimpanan aksesoris, meja jahit, parket yang disusun berjajar untuk tempat penyimpanan kain. Setelah mengalami perubahan dan penyesuaian, bangunan Dapoer-nya Paberik Beberapa diantara elemen interiornya yaitu tanaman, akuarium, meja dan kursi, dll.

Pada bangunan area produksi menggunakan penerangan lampu tl, sedangkna pada bangunan gudang tidak digunakan lampu karena tidak ada aktivitas di sore ke malam hari.

Pada bangunan Dapoer-nya Paberik menggunakan penerangan buatan menggunakan lampu lebih beragam dan sesuai dengan kebutuhan pengunjung. 


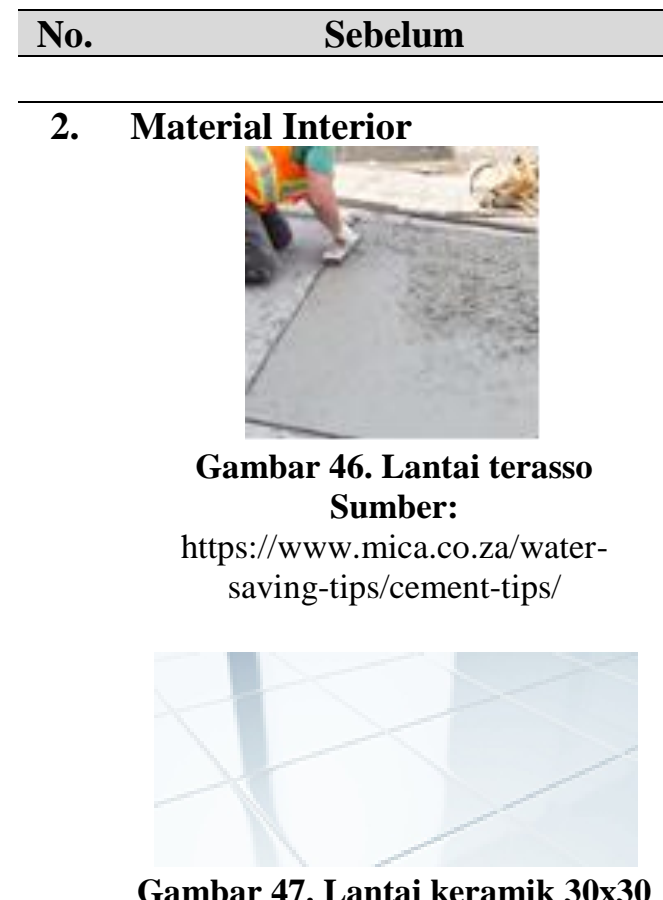

Sumber: https://harga.web.id/variasiharga-keramik-lantai-per-meterpersegi.info

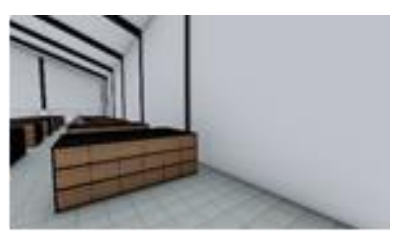

Gambar 51. Dinding sekat pabrik

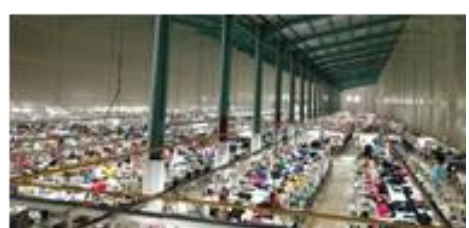

Gambar 54. Ceiling pabrik Sumber:

https://kucingputeh.blogspot.com/201 7/05/info-daftar-alamat-dan-nomortelepon_20.html

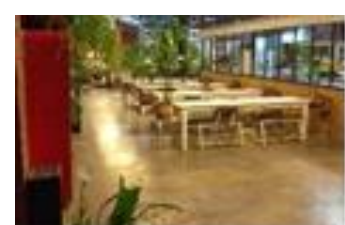

Gambar 48. Lantai acian halus

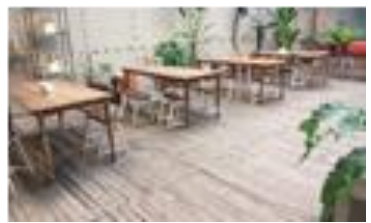

Gambar 49. Lantai parket

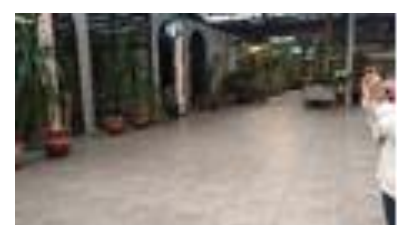

Gambar 50. Lantai Rock Tile $60 \times 60$

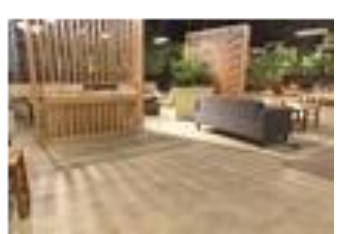

Gambar 52. Partisi kayu

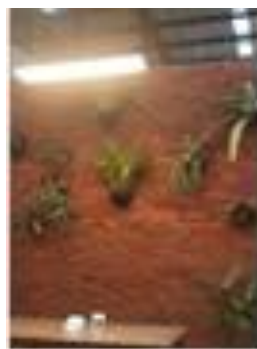

Gambar 53. Dinding sekat kafetaria

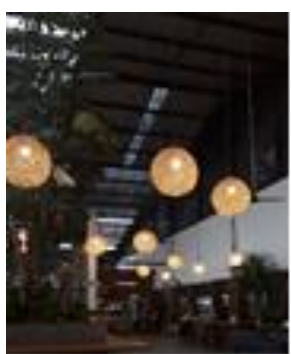

Gambar 55. Ceiling kafetaria
Digunakan material penutup lantai berupa terasso \& lantai keramik berukuran $30 \times 30 \mathrm{~cm}$ berwarna putih pada bangunan eksisting. Sedangkan Dapoer-nya Paberik menggunakan 3 finishing yang berbeda untuk pembatas zonasi ruang. Finishing yang digunakan berupa parket, rock tile, dan lantai acian halus.

Sekat yang pada awalnya terdapat pada bangunan eksisting sebagai pembatas massa bangunan kemudian ditiadakan. Pada bangunan kafetaria digunakan pembatas ruang berupa partisi kayu pada beberapa titik dalam ruang bangunan, seperti pada area makan zona 1 , meeting room, dan area servis.

Bangunan eksisting tidak menerapkan pengaturan ketinggian ceiling. Setelah bangunan dialih fungsikan, ditempatkan banyak gantungan baik berupa lampu maupun hiasan untuk mengatur ketinggian ruang yang terjadi. 


\section{Analisa Perubahan Kenyamanan Bangunan}

Tabel 3. Hasil analisa perubahan kenyamanan bangunan

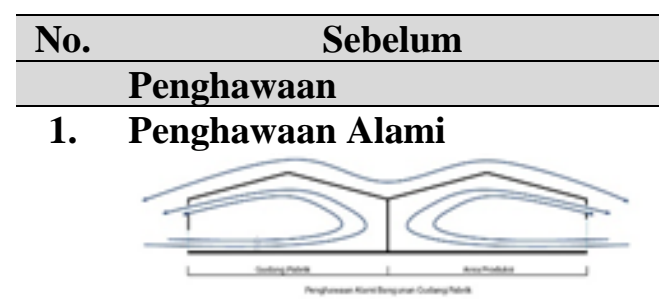

Gambar 56. Sirkulasi udara bangunan eksisting

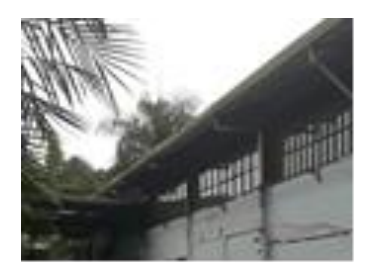

Gambar 58. Bukaan Dapoer-nya Paberik

\section{Penghawaan Butan}

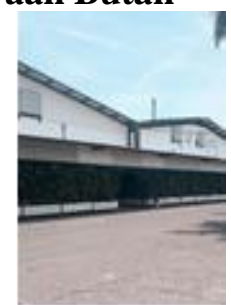

Gambar 60. Exhaust pada bangunan eksisting

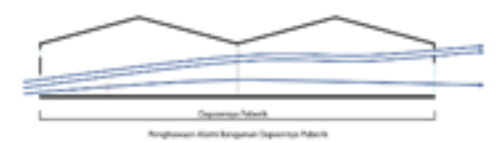

Gambar 57. Sirkulasi udara Dapoer-nya Paberik

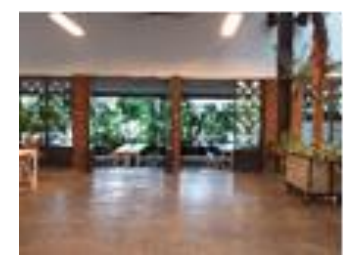

Gambar 59. Bukaan Dapoernya Paberik

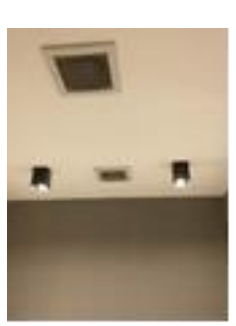

Gambar 61. Exhaust pada toilet Dapoer-nya Paberik

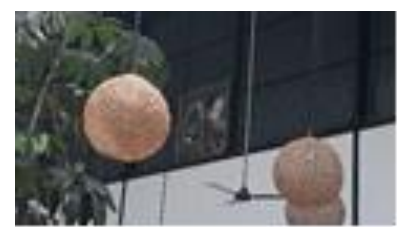

Gambar 62. Kipas angin dan exhaust
Bangunan Dapoer-nya Paberik membuat bukaan dengan jumlah yang cukup banyak pada bagian dinding bangunan. Pada bangunan sebelumnya, penghawaan yang terjadi tidak cukup baik, dan posisi inlet dan outlet berada pada sisi yang sama, sehingga mengalami penyesuaian selama proses peralihan fungsi bangunan.

Pada bangunan sebelumnya, terdapat exhaust yang berukuran besar pada dinding bagian atas bangunan gudang. Setelah melalui penyesuaian, exhaust tidak lagi dipergunakan pada bangunan Dapoer-nya Paberik. Pada bangunan saat ini digunakan kipas angin yang digantungkan berjajar, standing air conditioner, dan exhaust pada area toilet.

\section{Pencahayaan}

\section{Pencahayaan Alami}

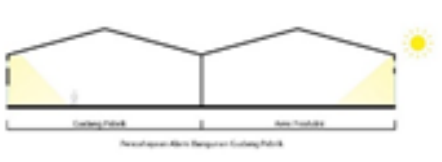

Gambar 63. Pencahayaan bangunan eksisting

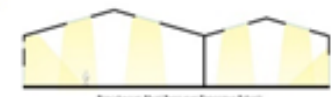

Gambar 64. Pencahayaan bangunan Dapoer-nya Paberik
Tidak semua bukaan pada fungsi bangunan lama digunakan pada Dapoer-nya Paberik. Pada bangunan eksisting terdapat glass block pada bagian dinding, namun tidak digunakan kembali pada bangunan baru. Perbedaan pencahayaan yang terjadi yaitu, pada bangunan eksisting, pencahayaan alami masuk ke dalam bangunan melalui bukaan cahaya yang berada pada dinding 


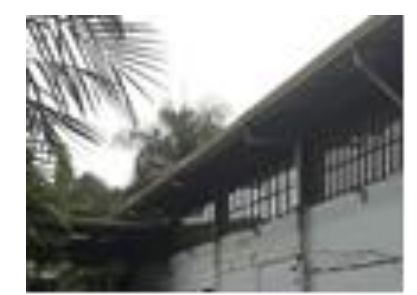

Gambar 65. Bouvenlight pada bangunan eksisting

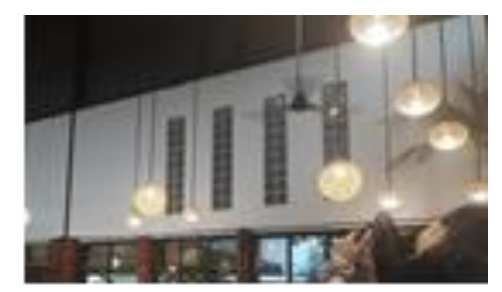

Gambar 67. Glass Block bangunan eksisting

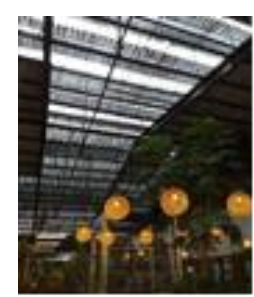

Gambar 66. Pencahayaan Atap Dapoer-nya Paberik

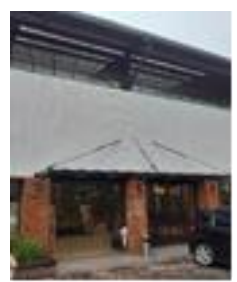

Gambar 68. Bukaan cahaya Dapoer-nya Paberik

bangunan, sedangkan pada bangunan kafetaria bukaan cahaya terdapat pada bagian dinding dan atap bangunan.

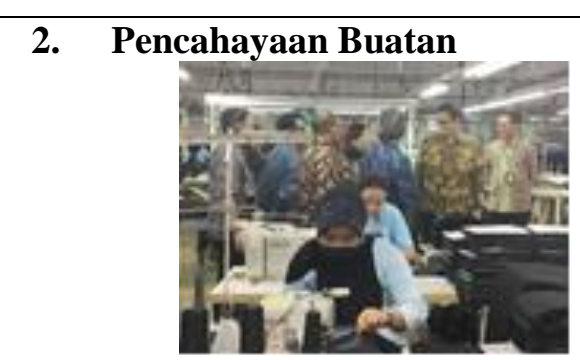

Gambar 69. Lampu bangunan eksisting

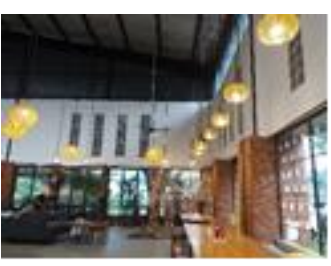

Gambar 70. Lampu kafetaria

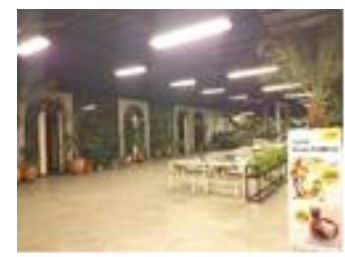

Gambar 71. Lampu kafetaria
Untuk memenuhi kebutuhan pengunjung juga digunakan artificial light berupa lampulampu gantung. Perbedaan terdapat pada jenis lampu yang digunakan. Pada bangunan Dapoer-nya Paberik lampu yang digunakan lebih beragam.

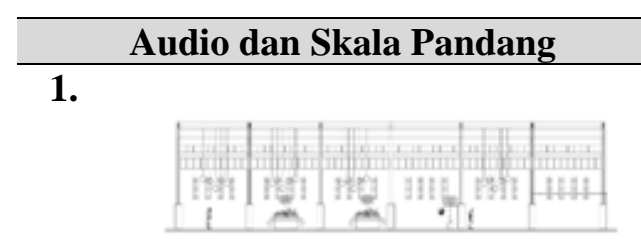

Gambar 72. Pengaturan skala pandang bangunan eksisting

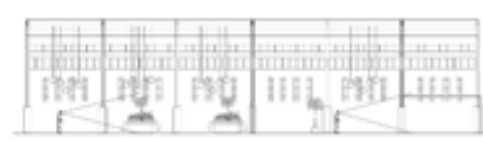

Gambar 73. Pengaturan skala pandang Dapoer-nya Paberik
Untuk meningkatkan kenyamanan, maka digunakan elemen interior pada dalam ruangan. Dengan demikian, skala pandang yang terbentuk akan lebih baik, dan akan mereduksi pantulan suara yang berlebih.

\section{SIMPULAN}

Pada kasus alih fungsi Gudang Pabrik menjadi Kafetaria terdapat beberapa penyesuaian terjadi agar tercipta kenyamanan bangunan. Beberapa perubahan yang terjadi pada bagian dalam bangunan, adalah desain ruang dalam, zoning ruang, penggantian material bangunan dan pengadaan furniture penunjang 
aktifitas kafetaria. Pada fasad bangunan juga dilakukan beberapa penyesuaian desain namun bentuk asli bangunan masih dapat dipertahankan.

Alih fungsi bangunan dinilai sebagai sebuah upaya yang baik untuk menjaga keberlangsungan sebuah bangunan dari pada menghancurkannya. Penghancuran banguan selain membuang biaya juga tidak sejalan dengan konsep sustainable design. Diharapkan keberhasilan pada Gudang Pabrik Badjoe dapat diterapkan pada bangunan-bangunan lain yang masih layak pakai dan terutama pada bangunan cagar budaya yang keberadaannya semakin berkurang seiring dengan berjalannya waktu.

\section{DAFTAR PUSTAKA}

[1] S. Lemmet, Buildings and Climate Change, Summary for Decision Maker. Paris: United Nations Environment Programme, 2009.

[2] L. Brebbia, C. A., Telles, J. C. F., Wrobel, Boundary Element Techniques, Theory and Applications in Engineering. Berlin: Springer-Verlag, 1984.

[3] S. A. Gatot, "Transformasi Bentuk Arsitektur Jawa," Spectra-eJurnao ITN Malamg, vol. 13, no. 25, pp. 13-26, 2015.

[4] C. Alexander, A New Theory of Urban Design. New York: Oxford University Press, 1987.

[5] D. Burchell, Robert W; Listokin, The Adaptive Reuse Handbook, First. Routledge, 1981.

[6] D. Kim, "Adaptive reuse of industrial buildings for sustainability : analysis of sustainability and social values of industrial facades," The University of Texas at Austin, 2018.

[7] P. Akadiri, Peter.O;Cinyio, Ezekiel.A;Olomolaiye, "Design of A Sustainable Building: A Conceptual Framework for Implementing Sustainability in the Building Sector," MDPI J., 2012. 